\title{
Políticas públicas educacionais: antigas reivindicações, conquistas (Lei 10.639) e novos desafios*
}

- Sônia Querino dos Santos e Santos** e Vera Lúcia de Carvalho Machado***

\section{Resumo}

O artigo "Políticas públicas educacionais: antigas reivindicações, conquistas (lei 10.639) e novos desafios" tem por base a dissertação de mestrado "População negra, relações inter-raciais e formação de educadoras/es: PENESB (1995-2007)", defendida por Sônia Querino dos Santos e Santos na PUC-Campinas em dezembro de 2007. Pretende considerar como o processo de identificação é construído no plano simbólico, nas opções curriculares, nas metáforas interditas que permeiam as idéias pré-concebidas que carregamos, pois nem sempre o diferente que vemos nos encanta, pelo contrário, muitas vezes, nos desafia e nos faz revisar nossas opções individuais e nossos valores.

Palavras-chave: Pertencimento. Diversidade étnico-racial. Práticas pedagógicas emancipatórias. Formação de educadoras/es.

\section{A Constituição de 1988 representa um marco para a construção de uma sociedade inclusiva. As mudanças na Constituição política são reflexos da correlação de forças entre grupos que disputam o poder, neste, os movimentos sociais - negros e indígenas em especial- ganham relevân- cia por assumirem a luta contra a opressão recebida em virtude de suas diferenças étnico-raciais e culturais. (SILVÉRIO, 2005, p. 88).}

Embora inseridas no atual contexto de incertezas e múltiplas escolhas, vemos igualmente importante repensar os paradigmas, bem como, questionar as representações sociais, políticas e religiosas que perpassam o consciente coletivo dos grupos sociais. Dessa maneira, não obstante o contexto neoliberal globalizador, o processo de desconstrução das "verdades estabelecidas" se dá em ambiente de inconformidade a partir do qual os movimentos reivindicatórios vêm mostrando a resistência de africanas/os e seus descendentes que não se submeteram ao sistema escravista, mas que se rebelaram contra a monocultura mental ${ }^{7}$ intrínseca à globalização.

Porquanto, a partir das duas últimas décadas do século $X X$, os movimentos sociais passam a expressar suas reivindicações em vista de coibir o tratamento discriminatório que recebem no seu cotidiano. Entre eles, encontram-se as reivindicações do movimento social negro na busca do reconhecimento da imensa contribuição da cultura de matriz africana, presente em nosso cotidiano, porém mal interpretada,

\footnotetext{
* O presente artigo faz parte da Dissertação de Mestrado: "População negra, relações inter-raciais e formação de educadoras/es: PENESB (1995-2007), defendida na PUC-Campinas.

** Mestra em Educação pela PUC-Campinas, Pesquisadora e Consultora sobre temas pertinentes às Questões Raciais. E-mail:squerino@hotmail.com

*** Doutora em Educação pela UNICAMP; coordenadora do Programa de Pós-Graduação em Educação da PUCCampinas

1 Metáfora utilizada pela autora Vandana Shiva (2003).
} 
estereotipada, bem como, banalizada e relegada ao fetichismo e à demonização pelas práticas pedagógicas e religiosas. Nesse contexto, as entidades de resistência negra surgem no interior de um caminho histórico, buscando respostas para cada período de dominação e exclusão.

Considerando o cenário brasileiro da harmonização racial, integrantes dos grupos do Movimento Negro são consensuais quanto à necessidade de repensar algumas noções e conceitos paradigmáticos incorporados no imaginário social. Dessa maneira, a luta pela liberdade é concebida como uma evolução da cidadania.

A ampliação da liberdade, para grupos socialmente excluídos, passa necessariamente pela identificação, por um lado, dos fatores sociais que são geradores e ou causadores da forma de exclusão e, por outro lado, pela identificação dos tipos de ações concretas e quais instituições sociais podem atuar de forma que se impeça sua reprodução. Uma das principais instituições sociais, considerada por muitos a instituição-chave das sociedades democráticas, é a escola, que sempre aparece como a que é capaz de preparar cidadãos e cidadãs para o convívio social. (SILVÉRIO, 2006, p. 7).

Denunciando a desigualdade racial existente no Brasil os movimentos sociais, na segunda metade do século XX, denominados identitários provocaram o debate sobre o lugar da diversidade e da diferença cultural no Brasil contemporâneo. Acreditamos que todas as dimensões da realidade estão articuladas e permeadas de saberes e, em nossa sociedade, a grande maioria dos saberes das culturas que constituem nosso jeito de viver tem origens no legado das civilizações africanas reelaboradas na dinâmica do dia-a-dia de nossas vidas, embora haja profundo desconhecimento e ausência da história e da saga africana no Brasil na educação de nível básico e nos níveis superiores de graduação e pós-graduação.

Por isso, quando se pensa no conhecimento, na pesquisa e na formação de uma intelectualidade no país, estamos já há algum tempo assumindo, não só no movimento negro, o papel de co-responsáveis pelas rupturas epistemológicas que levam um outro olhar para incluir a busca de nossas raízes, e as contribuições subjacentes às mesmas. Haja vista, os estudos sobre relações étnico-raciais e educação que têm contribuído para uma melhor compreensão dos jogos sociais e culturais que formam o tecido desigual de nossa sociedade.

É a partir da década de 70 que se inicia uma nova fase de pesquisa, cujos temas focalizam a posição dos negros na sociedade brasileira. Essas pesquisas, principalmente no âmbito das ciências sociais, enfatizavam aspectos relacionados à construção da identidade negra a partir do processo de modernização, bem como a interpretação criativa dos legados histórico-simbólico-educacionais oriundos do continente africano, recriados e reelaborados nos países afrodescendentes. Entre esses, o Brasil, seguido do Haiti, é alvo de pesquisa devido ao alto índice de africanas/os para cá trazidos na condição de escravos. 
Considerando que nos tempos atuais, como muito se discute sobre a fragmentação e desumanização dos seres humanos, é importante perceber que as hegemonias dominantes não só institucionalizaram as epistemologias peculiares aos saberes considerados científicos, como também impuseram a monocultura mental aos "restantes", "os outros", aos "dissidentes", àqueles cujos saberes são "primitivos" e "anticientífico". De acordo com Shiva (2003, p.25)

\begin{abstract}
A linearidade fragmentada do saber dominante rompe as interações entre os sistemas. O saber local resvala pelas rachaduras da fragmentação. É eclipsado como o mundo ao qual está ligado. Desse medo, o saber científico dominante cria uma monocultura mental ao fazer desaparecer o espaço das alternativas locais, de forma muito semelhante à das monoculturas de variedades de plantas importadas, que leva à substituição e destruição da diversidade local. O saber dominante também destrói as próprias condições para a existência de alternativas, de forma muito semelhante à introdução de monoculturas, que destroem as próprias condições de existências de diversas espécies.
\end{abstract}

As tentativas de invisibilizar a/o negra/o são tão sutis e refinadas que educadoras/es militantes dos movimentos negros têm investido esforços de pesquisa sobre as temáticas de discriminação e desvalorização da/o negra/o em espaços interativos, como a escola. Portanto, o respeito às diferenças implica uma reciprocidade na igualdade de relações.

Porquanto, uma breve retrospectiva dos avanços do movimento negro permite encontrarmos a aprovação da Lei 10.639 (BRASIL, 2003), em 09 de janeiro de 2003, que altera a Lei no 9.394 (BRASIL, 1996), de 20 de dezembro de 1996, que estabelece as diretrizes e bases da educação nacional, para incluir no currículo oficial da Rede de Ensino a obrigatoriedade da temática "História e cultura afrobrasileira". Haja vista, os inúmeros desafios encontrados para a implementação da Lei 10.639/03 podemos afirmar que as articulações em vista do reconhecimento de ser cidadão/cidadã na sociedade brasileira, seguem um ritmo histórico e, por vezes, algumas iniciativas antecedem, o "estabelecido por Lei", haja vista os trabalhos de conscientização desenvolvidos à margem dos espaços escolares por militantes dos movimentos negros.

Portanto, no contexto das diversas culturas, as diferenças e semelhanças foram ganhando significados distintos. Assim, a questão de pertencimento racial deve ser considerada no seu aspecto mais amplo, considerando principalmente a construção social, histórica, política e cultural das diferenças.

Embora a diversidade cultural esteja presente em todas as sociedades, a questão racial no Brasil localiza-se num amplo e complexo campo, cujo interesse não é algo particular às pessoas que se identificam a esse grupo étnico-racial, ou a militantes dos movimentos negros, antes, é uma questão pertinente a toda a sociedade brasileira e toda a humanidade. 
Por isso, para compreender a relação raça e etnia algumas estudiosas/os adotam a expressão "étnico-racial", na tentativa de abarcar tanto a dimensão cultural (linguagem, tradições, ancestralidade), quanto as características raciais visivelmente observáveis, tais como cor da pele, tipo de cabelo, entre outros.

A tensão entre um ideário anti-racista, que corretamente negava a existência biológica das raças, e uma ideologia nacional, que negava a existência do racismo e da discriminação racial, acabou por se tornar insuportável pelos fatos. É justamente a partir daí que aparece a necessidade de teorizar as "raças" como o que elas são, ou seja, construtos sociais, formas de identidades baseadas numa idéia biológica errônea, mas eficaz, socialmente, para construir, manter e reproduzir diferenças e privilégios.

Se as raças não existem num sentido estritamente realista da ciência, ou seja, se não são um fato do mundo físico, são, contudo, plenamente existentes no mundo social, produtos de formas de classificar e de identificar que orientam as ações humanas (GUIMARÃES, 1999, p. 67).

Tomadas em conjunto, as três escolas do pensamento racista (etnológico-racista; escola histórica; darwinismo-social) influenciaram sobremodo os brasileiros que se davam ao trabalho de pensar sobre o problema racial. Para Skidmore(1976), o Brasil era vulnerável às doutrinas racistas, uma vez que tais doutrinas eram parte vital da civilização norte-americana tão ardentemente admirada. Nesse sentido, quanto mais os brasileiros tomavam conhecimento das últimas idéias geradas da Europa, tanto mais ouviam falar da inferioridade do negro e do índio.

Consequentemente, o processo de construção da identidade negra em uma sociedade como a brasileira passa pelo reconhecimento e pertencimento. $E$, reconhecer-se ou assumir-se negro no Brasil é uma decisão de coragem, pois quem quer ser considerado "feio" e portador de uma cultura "inferior"? Tais inquietações estão enraizadas no imaginário de negros e não-negros, como conseqüências das representações sóciopolítico-culturais e significações do que é ser negro no Brasil? Assim, a representação do "ser negro" foi marcada pela significação de quem é superior e de quem é inferior.

Nesse contexto, ser negro possui vários significados, que resulta da escolha da identidade racial que tem a ancestralidade africana como origem, ou seja, assumirse negra/ negro no Brasil é, essencialmente, um posicionamento político.

Assumir a identidade racial negra em um país como o Brasil é um processo extremamente difícil e doloroso, considerando-se que os modelos "bons", "positivos" e de "sucesso" de identidades negras não são muitos e o respeito 'a diferença em meio 'a diversidade de identidades raciais/ étnicas inexiste (OLIVEIRA, 2004, p. 57).

Conseqüentemente, no "país mestiço", chamado Brasil, ser negra/ ser negro, além de uma questão de coragem, é uma escolha de identidade: a da ancestralidade africana, que como atenta Silva (2005, p. 44) defendendo a idéia do filósofo Steve Biko, líder assassinado no combate ao apartheid da África do Sul: "ser negro não é uma questão de pigmentação; ser negro é reflexo de uma atitude mental". Portanto, auto-declarar-se negro/negra é essencialmente, um posicionamento político. 
No rol das reivindicações e conquistas, a temática sobre desigualdade racial passou a interessar à imprensa oficial brasileira, em função da III Conferência Mundial contra o Racismo, Discriminação Racial, Xenofobia e Intolerância Correlata, realizada em 2001, período no qual passou a divulgar mais informações sobre a questão racial brasileira.

A partir da Conferência em Durban/ África do Sul, a questão racial reveste-se de grande complexidade, embora a Constituição de 1988 tenha deixado explícita a idéia de igualdade em todos os sentidos, afirmando inequivocamente a isonomia racial (art. $5^{\circ}$, caput) incriminando firmemente a prática do racismo (art. 5०, XLII)

Art. $5^{\circ}$ Todos são iguais perante a lei, sem distinção de qualquer natureza, garantindo-se aos brasileiros e aos estrangeiros residentes no País a inviolabilidade do direito à vida, à liberdade, à igualdade, à segurança e à propriedade, nos termos seguintes:

XLII - a prática do racismo constitui crime inafiançável e imprescritível, sujeito à pena de reclusão, nos termos da lei. (BRASIL, 1988).

No Brasil a exclusão social de que os negros são as principais vítimas deriva, sobretudo, da má distribuição de recursos públicos, principalmente, no âmbito da educação. Para Gomes (2005, p. 58-59):

[...] a educação é a mais importante dentre as diversas prestações que o indivíduo recebe ou tem legítima expectativa de receber do Estado. Trata-se, de um bem escasso [...].

Agir2 "afirmativamente" significa ter consciência do problema e tomar decisões coerentes com o imperativo indeclinável de remedia-los. Além de vontade política, que é fundamental, é preciso entender que a questão é de vital importância para que o País se imponha no cenário internacional e ocupe o espaço, a posição e o respeito que a sua história, o seu povo, suas realizações e o seu peso político e econômico recomendam.

Embora, a utilização do conceito de raça suscite críticas, devido a seus antecedentes históricos e acadêmicos, a categoria raça foi e continua sendo uma categoria central para a formulação e definição de políticas públicas de Educação. Brota desse impasse uma pergunta: se para as ciências biológicas raça está superado, por que a insistência, em particular do movimento negro, em usá-lo como um paradigma da luta contra a opressão de base racial/étnica, ou seja, do racismo?

Em resposta, crê-se que

[...] o uso da categoria "raça" pelo movimento negro justifica-se por questões políticas, iá que o racismo existe e é uma prática que tem por base não apenas a existência das raças, mas que as "nãobrancas" são inferiores. (OLIVEIRA, 2004,p. 59).

2 Cf. Joaquim B. Barbosa Gomes (2005, p. 56), as ações afirmativas têm como objetivo não apenas coibir a discriminação do presente, mas sobretudo eliminar os "efeitos persistentes" [...]. 
Para Guimarães (2006) a América Latina passou por ampla reforma constitucional a partir dos anos 1990 e, isso explica a reconstrução do Estado democrático de direito depois das duas décadas de autoritarismo, de meados de 1960 até meados da década de 1980. Nesse sentido, as reformas constitucionais no que toca às diversidades raciais, trouxeram como novidade a concepção de sociedades e nações pluriétnicas e multiculturais.

Reestabelecida a vida democrática em 1985, o Estado tentará por um curto tempo restabelecer o antigo jogo de classes, tentando relacionar-se com os novos movimentos sociais a partir dos partidos políticos, da ampliação do seu próprio aparelho e do aggiornamiento de sua legislação (GUIMARÃES, 2006, p. 277).

E reitera alguns avanços e conquistas, tais como, a criação da Fundação Cultural Palmares, em 1988, e a instituição de Zumbi como herói nacional, como também a criminalização do racismo, regulamentada pela lei 7.716 de 1989 (BRASIL, 1989); enquanto marcos simbólicos.

Haja vista, o cenário sociopolítico e histórico do Brasil foi marcado por intenso trabalho e articulação do movimento negro que, a partir de 1985, organizou encontros municipais e estaduais com o objetivo de refletir a participação do negro no processo constituinte. Entre esses, destaca-se o Primeiro Encontro Estadual "O negro e a constituinte", realizado em julho de 1985 na Assembléia Legislativa de Minas Gerais.

As reflexões de 1986 culminaram na realização da Convenção Nacional "O negro e a Constituinte", da qual se originou um documento sintetizando os Encontros Regionais ocorridos em várias unidades da Federação que pautaram a importância e a reivindicação de que a Assembléia Nacional Constituinte (ANC) deveria proporcionar um espaço para atuação do movimento negro com objetivo de que a próxima Constituição Federal pudesse refletir as discussões até então realizadas por esse movimento.

Segundo documentos, uma das principais reivindicações apresentadas pelo movimento negro no âmbito da 'Subcomissão de negros, populações indígenas, pessoas deficientes e minorias ${ }^{3}$, foi a educação, ou seja, a proposta de que o texto da Constituição Federal de 1988 afirmasse o compromisso da educação com o combate ao racismo e todas as formas de discriminação, com a valorização e respeito à diversidade assegurando a obrigatoriedade do ensino de história das populações negras do Brasil, como uma das condições para o resgate de uma identidade étnico-racial e a construção de uma sociedade plurirracial e pluricultural.

Essas propostas foram inicialmente aceitas na Assembléia Nacional Constituinte e inseridas no anteprojeto (BRASIL, 1987b) elaborado e aprovado nessa Subcomissão:

Art. $4^{\circ} \mathrm{A}$ educação dará ênfase à igualdade dos sexos, à luta contra o racismo e todas as formas de discriminação, afirmando as características multiculturais e pluriétnicas do povo brasileiro.

3 Cf. Silvério (2005, p. 89), os trabalhos organizaram-se inicialmente em Subcomissões, que eram responsáveis pela preparação de anteprojetos básicos, esses eram emendados e votado no âmbito das próprias Subcomissões, em uma primeira etapa; na segunda etapa eram consolidados e novamente votados em Comissões Temáticas e finalmente reunidos em um texto completo na Comissão de Sistematização. Só então o texto seria apreciado, emendado, se fosse o caso, e votado pelo Plenário da Assembléia Nacional Constituinte. 
Art. $5^{\circ} \mathrm{O}$ ensino de "História das Populações Negras do Brasil" será obrigatório em todos os níveis da educação brasileira, na forma que a lei dispuser.

Ao ser submetido à Comissão Temática da Ordem Social(BRASIL, 1987a), sofre alteração,

Art. 85 O poder público reformulará, em todos os níveis, o ensino de história do Brasil, com o objetivo de contemplar com igualdade a contribuição das diferentes etnias para a formação multicultural e pluriétnica do povo brasileiro.

Por fim, aprovado na Comissão de Sistematização (BRASIL, 1987b)

Art. 242 ensino de história do Brasil levará em conta as contribuições das diferentes culturas e étnicas para a formação do povo brasileiro.

A justificativa apresentada para a retirada dessa proposta do texto constitucional foi a de que, por se tratar de uma questão muito particular, deveria ser abordada em legislação complementar específica. No caso brasileiro, as mudanças em curso permitem levantar a hipótese de que vivemos numa transição de uma sociedade na qual a representação monocultural está dando lugar a uma representação social que cotidianamente se revela profundamente dinâmica e multicultural.

É neste cenário que o movimento social negro atuou intensamente no centenário da Abolição da Escravatura. Ocorreram eventos no Brasil inteiro, foram publicadas pesquisas com indicadores sociais e econômicos demonstrando que a população negra estava em piores condições que a população branca, comparando-se qualquer indicador: saúde, educação, mercado de trabalho, entre outros. Constroem-se com isso novos argumentos para romper com a idéia de que todos são tratados do mesmo modo no Brasil.

Em 1995, as manifestações comemorativas aos 300 anos da morte de Zumbi culminam com a Marcha de Zumbi dos Palmares ${ }^{4}$ contra o racismo, pela cidadania e pela vida, na qual cerca de 10 mil negras e negros foram a Brasília com um documento (POR..., 1996) reivindicatório entregue ao então presidente Fernando Henrique Cardoso.

Participaram dessa marcha, que aconteceu no dia 20 de novembro, uma segunda-feira, 30 mil ativistas negros vindos de todos os cantos do país. Naquele mesmo dia, integrantes da Executiva Nacional da Marcha Zumbi dos Palmares foram recebidos pelo então presidente da República, Fernando Henrique Cardoso, em rápida solenidade no Palácio do Planalto. Na ocasião, foi entregue ao presidente um documento com as principais reivindicações do Movimento Negro, denunciando o racismo, defendendo a inclusão dos negros na sociedade brasileira e apresentando propostas concretas de políticas públicas.

4 Cf. Introdução do Documento entregue ao Presidente, em 1995. A Marcha Contra o Racismo, pela Cidadania e a Vida é uma iniciativa do Movimento Negro brasileiro e se constitui num ato de indignação e protesto contra as condições subumanas em que vive o povo negro deste país, em função dos processos de exclusão social determinados pelo racismo e a discriminação racial presente em nossa sociedade. Já fizemos todas as denúncias. O mito da democracia racial está reduzido a cinzas. Queremos agora exigir ações efetivas do Estado - um requisito de nossa maioridade política. 
A construção da Marcha ${ }^{5}$ dos 300 anos contou com a participação de centenas de entidades do Movimento Negro, espalhadas por todo o país, tendo também recebido o apoio de entidades sindicais, em especial às centrais nacionais de trabalhadores. A base da organização esteve sediada no Distrito Federal, sendo que o processo de mobilização foi intenso durante os quatro meses que antecederam a marcha.

De acordo com Santos (2005, p. 15),

Sob pressão dos movimentos negros, em 1995, o atual presidente Fernando Henrique Cardoso iniciou publicamente o processo de discussão das relações raciais brasileiras, admitindo oficialmente pela primeira vez na história brasileira, que os negros eram discriminados. Apesar desse primeiro passo, o reconhecimento oficial do racismo no Brasil pode-se dizer que até agosto de 2000 o governo brasileiro não havia empreendido grandes esforços para que a discussão e implementação de ações afirmativas entrassem na agenda política e/ou nacional brasileira.

Por conseguinte, na formulação de políticas educacionais - quando se discute a definição de um modelo educacional à "nação" brasileira - é o conceito de raça que implicitamente é discutido e renegociado.

A discussão em torno das relações raciais no Brasil é marcada por uma tensão entre interpretações opostas: uma que afirma e valoriza a convivência harmoniosa entre brancos e não-brancos, expressa na ausência de conflito racial violento, e outra, que demonstra a existência do preconceito racial. Essa tensão está presente em todo o debate público sobre o "racismo"b brasileiro.

Afinal, o processo identitário da população brasileira é marcado por tensão, por quê? Nesse contexto necessitamos compreender o conceito de humanidade construído socialmente em vista de classificar os "recém-descobertos" - índios e negros, no qual, os europeus se perguntavam: esses "recém-descobertos" são seres humanos como nós? Como ponto de partida, explicitaremos os conceitos de raça e etnia e, em seguida, veremos as teorias racistas que influenciaram o pensamento científico brasileiro, bem como a classificação racial usada pelo Instituto Brasileiro Geográfico de Estudo (IBGE).

O trabalho de Guimarães revela-se de fundamental importância quando transitamos pelas concepções de raça e etnia. Considerando a amplitude e profundidade da sua produção sobre o tema, apresentamos a distinção entre os termos raça e etnia, visto que inúmeras vezes, estes são assumidos ou rejeitados por desconhecermos o contexto sociológico que redimensionou tais conceitos. O autor (GUIMARÃES, 2003, p. 93) inicia sua abordagem indicando a necessidade de "fazermos sempre uma distinção, nas Ciências Sociais, entre dois tipos de conceitos: os analíticos, de um lado, e os que podemos chamar de "nativos"; ou seja, trabalhamos com categorias analíticas ou categorias nativas."

5 A educação aparece, mais uma vez, como um dos elementos centrais desse programa, na crítica à centralidade dos estudos e referenciais do mundo ocidental nos currículos escolares, que acabam por permear também a estrutura do sistema educacional que atende a esse modelo, na medida em que seu contexto apresenta uma lógica cujos pressupostos reiteram estereótipos e confirmam preconceitos. Aponta-se nesse programa a necessidade de reorganização da escola a partir da diversidade que promova uma revisão de toda a estrutura educacional e a necessidade de ações afirmativas na educação. 6 De acordo com Seyferth (2001) "o racismo se afirmou como conceito científico no século XIX e, justificava claramente a dominação imperialista das raças classificadas como inferiores, isto é, não brancas". 
No decorrer do texto sobre raça, o autor (GUIMARÃES, 2003, p. 99) nos diz

a idéia de raça, tal como a temos hoje, pressupõe uma noção chave para a ciência moderna - a de natureza imanente - segundo a qual da natureza emana um determinado caráter, uma determinada psicologia, uma determinada capacidade intelectual. A idéia científica de que a natureza se desenvolve propulsionada por seus próprios mecanismos internos é imprescindível para essa idéia moderna de raça. Feita essa distinção, não se pode negar que a palavra "raça" é anterior a esta idéia moderna. Mas trata-se então de uma idéia não científica, inteiramente teológica, que no Brasil, nos Estados Unidos e em outros lugares justificou a escravidão.

Portanto, no contexto das diversas culturas, as diferenças e semelhanças foram ganhando significados distintos. Assim, a questão de pertencimento racial deve ser considerada no seu aspecto mais amplo, considerando principalmente a construção social, histórica, política e cultural das diferenças.

Embora a diversidade cultural esteja presente em todas as sociedades, a questão racial no Brasil localiza-se num amplo e complexo campo, cujo interesse não é algo particular às pessoas que se identificam a esse grupo étnico-racial, ou a militantes dos movimentos negros, antes, é uma questão pertinente a toda a sociedade brasileira e a toda a humanidade.

Por isso, para compreender a relação raça e etnia algumas estudiosas/os adotam a expressão "étnico-racial", na tentativa de abarcar tanto a dimensão cultural (linguagem, tradições, ancestralidade), quanto as características raciais visivelmente observáveis, tais como cor da pele, tipo de cabelo, entre outros.

Segundo Hall (2003) "raça" é uma construção política e social. É a categoria discursiva em torno da qual se organiza um sistema de poder socioeconômico, de exploração e exclusão - ou seja - o racismo. Contudo como prática discursiva, o racismo possui uma lógica própria. Tenta justificar as diferenças sociais e culturais que legitimam a exclusão racial em termos de distinções genéticas e biológicas, isto é, na natureza.

Portanto, Stuart Hall (2003) entende "raça" como uma categoria organizadora das formas de falar, dos sistemas de representação e práticas sociais que utilizam um conjunto frouxo, freqüentemente pouco específico, de diferenças em termos de características físicas, correspondendo, portanto, a marcas simbólicas a fim de diferenciar um grupo de outro.

Para Seyferth (2001), na maioria das sociedades humanas a palavra raça evoca classificações de ordem física utilizadas para marcar diferenças de ordem social. Ou seja, o "significado biológico de raça é deformado por concepções errôneas acerca da hereditariedade, que levam à classificação e hierarquização de grupos e pessoas". Neste sentido, o que é apenas diferente torna-se desigual.

A noção de raça assume caráter ambíguo, por ser tomada como símbolo de diferenciação de grupos na sociedade, isto é, as características raciais têm função de signo de uma condição social inferior. Dois destes signos são particularmente enfatizados, a nível popular: 
a cor (da pele) e o sangue, tomados como metáfora da hereditariedade. Juntamente com eles, existe toda uma tendência reducionista nas sociedades multirraciais segundo a qual a raça determina a cultura e, por extensão, a civilização (SEYFERTH, 2001, p. 1).

A noção de raça tem, pois, relevância no sentido em que é usada para separar, na sociedade, as chamadas minorias. Como critério de diferenciação de grupos (étnicos), porém, nunca é unívoca. As minorias sejam elas raciais, nacionais ou étnicas, são tanto definidas por critérios exclusivos como inclusivos, e esses critérios comportam elementos que estabelecem uma especificidade cultural (simbólica ou não), racial, ambas, ou até outras.

Para a autora a raça em si, como conceito biológico, não é objeto de estudo das ciências sociais, porém, ao estudar as relações raciais não se pode prescindir do conceito de raça, científico ou popular - ainda que este seja carregado de preconceitos.

A utilização do termo "raça" pelo Movimento Negro e por diversas estudiosas/os não está alicerçada à idéia de que existam raças superiores e inferiores. Segundo Munanga e Gomes (2006, p. 175),

os grupos lançam mão do conceito, dando-lhe um outro significado, relacionado ao reconhecimento da diferença entre grupos humanos, sem atribuir qualidades positivas ou negativas, ao reconhecimento da condição das origens ancestrais e identidades próprias de cada um deles. Ou seja, ao utilizar o conceito raça negra no Brasil, denunciam o racismo, alertando para o fato de que aqueles classificados como negros (pretos, pardos, morenos e mulatos) estão expostos a condições de vida, educacionais e salariais extremamente desiguais quando comparados ao segmento branco da população brasileira.

Com relação ao termo "etnia", alguns intelectuais, educadoras(es) e acadêmicas(os) consideram seu conceito mais adequado por não carregar o sentido biológico atribuído à raça. Dessa forma, o termo é usado para se referir ao pertencimento ancestral e étnico-racial dos negros e outros grupos em nossa sociedade. Os que partilham dessa visão, entendem por etnia, segundo Munanga e Gomes (2006, p. 177),

um grupo possuidor de algum grau de coerência e solidariedade, compostos por pessoas conscientes, pelo menos em forma latente, de terem origens e interesses comuns. Um grupo étnico não é mero agrupamento de pessoas ou de setor da população, mas uma segregação consciente de pessoas unidas ou proximamente relacionadas por experiências compartilhadas.

Guimarães (1999, p. 67) afirma "se os negros considerarem que raças não existem, acabarão também por achar que eles não existem integralmente como pessoas, já que é como raça que são parcialmente percebidos e classificados por outros."

Ao situar o posicionamento de pesquisadoras/es, tendo a posicionar-me ao uso do termo raça, com as implicações dialético-crítica que o mesmo encerra. Creio ser 
importante o resgate do contexto histórico-sociopolítico no quais os termos foram elaborados, contudo, mais importante ainda, nos posicionarmos criticamente com relação ao uso dos termos em questão, ou seja, raça e/ou etnia.

Possivelmente os desafios atuais estejam nos impulsionando a tal posicionamento, mesmo considerando o "uso politicamente aceitável do termo etnia". Ou seja, na perspectiva em prol das relações inter-raciais, a opção política de um ou outro termo não nos fecha ao diálogo, ao contrário, motiva-nos para a discussão teórico-prática, fundamentada no rastro histórico-político-social no quais os termos foram cunhados.

Portanto, revela-se de fundamental importância pautarmos nossos "acordos e/ou desacordos" às questões que nos envolvem, enquanto cidadãs/os brasileiras/os, nos lastros de experiências em pesquisas e construção do conhecimento sobre essas realidades, a partir de procedimentos metodológicos que dêem conta de ler as especificidades criadas por estas diferenças.

Na luta por reconhecimento e implantação de políticas públicas que favoreçam os afrodescendentes, a trajetória da intelectualidade negra é marcada por articulações e lutas historicamente conhecidas contra o sistema colonial escravista, reivindicações pós-abolicionistas, organização dos quilombos, sobrevivência das religiões e culturas africanas.

De acordo com Siqueira (2006, p. 33-36) revisitando nosso passado, relembraremos algumas das iniciativas que interferiram na regulamentação da Lei 10.639/03 (BRASIL, 2003). ${ }^{7}$ É, justamente na década de 80 que irão eclodir várias experiências (ROSEMBERG; PINTO, 1987), ${ }^{8}$ de alteração curricular, propondo a revisão curricular e à Inclusão da história e da cultura do negro no currículo em diversos Estados do Brasil.

\footnotetext{
7 Em 1914 surge a $1^{a}$ organização Sindical de Negros. Dela participaram de forma expressiva e determinantes as mulheres negras em Campinas,SP; 1915 surge o Menelick, o primeiro jornal de negros da capital paulista; 1916 criado o Centro Cívico Palmares, em São Paulo, cujo objetivo, entre outros, era criar uma biblioteca só para negros; 1923 surge o Jornal O Clarim da Alvorada, cujo objetivo era refletir sobre as lutas dos antepassados e organizar a comunidade para dar continuidade a Saga; 1929 surge o Jornal Quilombo, na cidade do Rio de janeiro; 1931 a Frente Negra Brasileira (FNB) um movimento de massas, de protesto contra a discriminação racial, a exclusão dos negros dos empregos, dos sistemas de educação, contra a segregação do negro dos lugares públicos. A maior representatividade da ação da Frente era constituída de mulheres; 1944 Abdias do Nascimento funda no Rio de Janeiro o Teatro Experimental Negro (TEN) a primeira entidade do Movimento afro-brasileiro a ligar, na teoria e na prática, a afirmação e o resgate da cultura brasileira de origem africana com a atuação política. Introduzindo assim, uma nova abordagem à luta do século;1950, no Rio de Janeiro, aprovada a Lei Afonso Arinos, que condena como contravenção penal a discriminação de raça, cor e religião. Também é o Conselho Nacional de Mulheres Negras; 1969, o governo do general Emílio G. Médici proíbe a publicação de notícias sobre movimento negro e a discriminação racial;1971 surge em Porto Alegre o Grupo Palmares;1974 fundado em Salvador-Bahia o bloco afro llê Aiyê; 1978 consolidação do Movimento Negro Unificado em São Paulo. Também foi declarado o dia 20 de novembro como dia da consciência Negra;1978 - O Movimento Negro Unificado - Bahia (MNU) faz solicitação ao MEC para a inclusão de História da África nos currículos de ensino nas escolas brasileiras.

8 Em 1980 o Centro de Cultura do Maranhão, criado em 79, promoveu a I Semana do Negro, no período de 13 a 19 de maio; Em 1982 foi criado o Conselho de Participação e Desenvolvimento da Comunidade Negra, em São Paulo, resultado da articulação de diversos grupos de militantes; Em 1983 o Projeto Palmares foi implantado em União dos Palmares após entendimento entre a Associação Cultural Zumbi e Secretaria de Cultura do MEC; Em 1983 o Centro de Estudos AfroOrientais (CEAO) ligado à Universidade Federal da Bahia (UFBA) expõe ao Conselho Estadual de Educação a solicitação para incluir a Disciplina "Introdução aos Estudos Africanos", nos currículos de $1^{\circ}$ e $2^{\circ}$ grau da rede estadual de ensino; Em 1984, vários grupos dos movimentos negros assinaram um documento solicitando ao Secretário da Educação do Estado da Bahia a inclusão nos currículos de $1^{\circ}$, e $2^{\circ}$ grau da Disciplina "Introdução aos Estudos Africanos", ao tempo em que referendavam igual solicitação do CEAO em 1983; No ano de 1985, ocorreu uma revisão curricular na rede municipal de ensino de São Paulo. Nesse ano, a Comissão de Educação do Conselho da Comunidade Negra sugeriu à Fundação Carlos Chagas uma pesquisa sobre a situação educacional dos negros em São Paulo. (ROSEMBERG; PINTO, 1987).
} 
A partir do recorte descrito, podemos dizer que militantes do movimento negro propõem ir além da denúncia e partir para apresentação de propostas, pesquisas e formação de professores na luta contra a discriminação racial na escola. Gomes (1997) argumenta sobre o questionamento das políticas homogeneizadoras e sobre a necessidade de se repensar a estrutura excludente da escola de modo a garantir, a população excluída, o acesso e a permanência com êxito.

Pensar a educação brasileira do ponto de vista do povo negro é compreender que o processo de exclusão deste segmento étnico/ racial não acontece somente em nível ideológico, que se faz notar na reprodução de estereótipos racistas nos livros didáticos, na baixa expectativa do professor em relação ao aluno negro, na veiculação de teorias racistas, na folclorização da cultura negra, mas também na existência de um sistema de ensino pautado em uma estrutura rígida e excludente que representa campo fértil para a repetência e a evasão. (GOMES, 1997, p. 24).

Todavia, a questão do negro na Educação é um dos mais graves e pendentes problemas da nossa sociedade. As desigualdades raciais são evidenciadas de modo extremamente acentuado em nossas escolas, desde a formação básica, perpassando pelo Ensino Fundamental e Médio, e Estudos Superiores de Graduação e Pós-Graduação. É lugar comum que, no Brasil, é reduzido o número de estudantes negros que chegam à Universidade e que são a "exceção que confirmam a regra".

Nessa perspectiva, necessitamos capacitar professoras/es educando-as/as para serem produtoras/es culturais, ou seja, para lidar com a diversidade como uma atividade inconclusa e aberta à contestação, em vista de uma práxis pedagógica preocupada com as leituras das imagens, dos discursos legitimados e das vozes silenciadas.

Esse trabalho vem sendo realizado pelo Programa de Educação sobre o Negro na Sociedade Brasileira (PENESB), aprovado pela Resolução $n^{\circ}$. 121/95, do Conselho de Ensino e Pesquisa do Centro de Estudos Sociais Aplicados da Faculdade de Educação da Universidade Federal Fluminense (UFF) que inicia suas atividades a partir de agosto de $1995^{\circ}$. O PENESB está inserido no rol das lutas protagonizadas pelas denúncias do movimento negro brasileiro que, ao longo da história, reivindica o direito à educação. Daí que

a atribuição de significados sociais à diversidade humana a hierarquiza, provocando as desigualdades entre negros e não-negros em todos os setores sociais com forte projeção na educação na qual são evidenciados claramente os efeitos da discriminação contra o negro na educação. A projeção das desigualdades entre negros e não negros na educação está a exigir uma formação dos profissionais da educação que dê conta da eliminação deste problema que atinge toda a humanidade. (OLIVEIRA, 2006, p. 128).

9 Orientando-se pelo objetivo de realizar pesquisas sobre a dimensão racial do fenômeno educativo de modo paralelo à disseminação dos conhecimentos sobre o tema, junto à população em geral e em especial junto aos profissionais da educação, interferindo na sua formação inicial e continuada. (Cf.Relatório PENESB, 1996 - 1997) 
Há muito por fazer no campo das práticas pedagógicas com recorte racial. Contudo a contemporaneidade das reivindicações antigas e novas revela uma construção do imaginário social brasileiro menos sectarista. Os avanços demonstrados com o cenário pré-constituinte, a Carta Magna de 1988, a Marcha Zumbi dos Palmares, a aprovação da Lei 10.639/2003 (Brasil, 2003), e do Parecer 000/2004 estão construindo a tão sonhada democracia a partir dos retalhos de uma longa história de reivindicação e conquistas, protagonizadas pelo Movimento Negro.

Concordo com Silva (2005) ao chamar a atenção de educadores/as para a complexidade da educação da diversidade e na diversidade. Pois, segundo a autora, muito além dos procedimentos pedagógicos é requerido de quem se propõe a ensinar nessa perspectiva, conhecer sua história, ser sensível aos sofrimentos a que são constantemente submetidos, compreender sua visão de mundo, e aliar-se às lutas por seus direitos. Mais do que isto, precisa empenhar-se na educação de novas relações raciais, o que significa ter presente que estes não são problemas dos negros ou dos indígenas, mas de toda a sociedade brasileira.

Dessa maneira, um dos grandes desafios da escola consiste em proporcionar uma educação que respeite as diferenças existentes entre os sujeitos, valorizando-os em toda a sua diversidade. Para isso, faz-se necessário garantir a formação continuada de professores cujas práticas docentes conduzam o educando à autonomia intelectual, ajudando-o a alçar vôos, levantar hipóteses, argumentar, discutir os erros, projetar, planejar e vincular os conteúdos acadêmicos com o contexto histórico-político-social mais amplo.

Compreendo que o trato pedagógico da diversidade étnico-racial seja complexo e, além de exigir de nós o reconhecimento da diferença, exija também avançarmos na construção de práticas educativas que rompam com a idéia de homogeneidade e de uniformização que ainda impera no campo educacional.

As práticas pedagógicas serão emancipatórias quando extrapolarem os muros da escola e reavaliarem periodicamente o "fazer-pedagógico" inserido nos desafios das mudanças de valores, de lógicas e de representações sobre o outro, principalmente, aqueles que fazem parte dos grupos historicamente excluídos da sociedade.

Capacitar docentes para lidar com a diversidade significa fazer das diferenças um trunfo, explorá-las na sua riqueza, possibilitar a troca entre os grupos étnicos, entender que o acontecer humano é feito de avanços e limites. E que a busca de estabelecer relações dialógicas e valorativas do "outro" nos oriente para a adoção de práticas pedagógicas, sociais e políticas em que as diferenças sejam entendidas como parte de nossa vivência.

que significa, conforme Freire, "ler e re-ler o mundo" e, como seres inacabados, interagir em um mundo no qual caibamos todos com iguais possibilidades de ascensão e participação sociopolítica na sociedade e no mundo globalizado? É o que busco responder enquanto mulher negra nascida em um dos estados brasileiros com maior percentual da população negra. 
Portanto, para avançarmos nessas lutas a discussão do trato pedagógico dessas questões faz-se valer; a aproximar-se do corpo discente e do docente colhendo suas vozes e pareceres se impõem como embrião desafiador que possibilitará chegarmos ao cerne das questões relacionando-as na construção de diferentes identidades.

Compreendemos que essas mudanças de foco na formação de educadores exigem que os centros de formação capacite-os para lidar com esses problemas, portanto, os professores hoje, especialistas em Educação, raça e etnia, estão em comparação aos demais muito mais capacitados para contribuir, em seus respectivos estabelecimentos de atuação, para um mundo no qual o racismo, o preconceito e a exclusão dos negros e indígenas sejam páginas realmente viradas na história.

Enquanto as coordenadas para o sistema educativo estiverem em mãos de empresários, muitos docentes são obrigados a seguir as apostilas e ignorar os conflitos vivenciados nas salas de aula, pois o conteúdo previsto nas apostilas e nos livros precisa ser repassado em detrimento de outros assuntos, os quais os alunos "têm oportunidade de aprender fora da escola". Percebemos que urge a discussão sobre a construção de uma postura ética dos educadores no que diz respeito aos conflitos raciais na escola. Não dá para ignorá-los ou silenciar acreditando que esses existem "fora daqui", ou "talvez na escola vizinha".

As discussões sobre as relações raciais implicam modificações, perdas e recriações em nossas práticas pedagógicas. Esse processo vivenciado na escola, por ela sempre ter estado envolvida com a formação de cidadãs/cidadãos e, contribuir diretamente na construção das identidades sociais. Conseqüentemente isso a torna palco pelas mais diferentes vertentes e por distintos movimentos sociais na contemporaneidade.

Sabemos que o professor, em sua prática, na sala de aula ou fora dela, difunde idéias políticas sobre a sociedade quando expressa juízos de valor sobre justiça, liberdade, igualdade, etc. Da mesma forma, ao demonstrar padrões de comportamento como aceitáveis ou não, colabora para o controle social pela assimilação desses padrões pelos alunos. Esses padrões éticos podem ser de conformismo ou de mudança, de crítica ou de aceitação. Dessa maneira, o professor exerce de fato uma influência sobre a concepção política dos seus alunos frente à sociedade.

Na sociedade em que vivemos, onde predomina a ideologia neoliberal, esses padrões têm sido tratados abstratamente, subtraídos das condições da realidade e dos fatores econômicos, sociais e políticos geradores da sociedade concreta da qual fazem parte a escola, o professor e o aluno. São conceitos trabalhados ideologicamente, livres das condicionantes sociais, cada vez mais abstraídos das questões de classe, tendo em vista que a divisão da sociedade em classes tem sido colocada como fator superado somos todos cidadãos, quer dizer todos os que podem consumir.

Em nossa organização social, a escola tem estado a serviço de uma determinada classe, que não é a oprimida, o que leva diversos documentos do movimento negro a afirmarem que o conjunto ideológico por ela transmitido tem servido para justificar as desigualdades, ocultando e mascarando as contradições e os antagonismos da sociedade. 
A seleção de conteúdo educacional brasileiro traz embutido em sua prática um arcabouço ideológico racista, apontando os negros como um povo extinto, visto que citados nos livros didáticos sempre no passado, incutindo no educando negro o perfil de ser inferior, deixando como alternativa o "embranquecimento". Nesse sentido, a dificuldade em autodeclarar-se negra, negro é conseqüência do desprezo pelos valores culturais dos afro-brasileiros.

Vários pesquisadores têm discutido os possíveis caminhos que podem ser traçados pela escola no tratamento da diversidade étnico-racial, para que os currículos incorporem essa questão de maneira menos descontextualizada das condições sociais e mais ativa, apresentando um rol de propostas baseadas fundamentalmente numa reflexão sobre a práxis educativa de alunos e professores.

À revelia das propostas de formação inicial e/ou continuada das instituições de ensino e/ou das mantenedoras das redes de ensino, diversos profissionais da educação têm empreendido esforços na busca da produção de conhecimentos que rompam com a lógica reprodutivista da escola, a qual leva a compactuar e reforçar o sistema racista de nossa sociedade.

Concebemos que se faz necessário refletir coletivamente, com grupos de professores, que vêm desenvolvendo propostas em sua área de trabalho, visando a dar conta da produção de um conhecimento incipiente no meio acadêmico, que oriente sua ação numa perspectiva de reflexão crítica frente à organização excludente da sociedade e à manutenção do seu status quo.

Para tanto, é fundamental a discussão dos Projetos Pedagógicos das unidades educacionais tanto de Educação Infantil, quanto de Ensino Fundamental que incluem algum tipo de trabalho com a questão racial, além de estabelecer processos de análise e reflexão com profissionais que participam de grupos de formação ligados ao tema.

Entendemos que se faz necessário participar na sistematização desse conhecimento que vem sendo produzido nas escolas, contribuindo com a reflexão da ação a partir também da nossa prática em cursos de formação de professores e grupos de trabalho, onde devemos discutir propostas que vão desde a inclusão de temas no currículo, até a pesquisa da formação social do bairro/região onde está inserida a escola. É esse produto que devemos estar sistematizando e pretendemos que venha a servir de subsídio para reflexão da prática de outros educadores.

Embora as políticas educacionais que imperam na América Latina, desde os anos 90, tenham favorecido as empresas multinacionais, grandes investimentos e lucros em nome da Educação, nossos estudantes, outrora educandos, hoje considerados "clientes", são merecedores de uma formação educacional pertinentes aos desafios hodiernos. 


\section{Referências}

BRASIL. Comissão da Ordem Social. Anteprojeto da Comissão. Brasília, DF: Centro Gráfico do Senado Federal, 1987a.

BRASIL. Comissão de Sistematização. Anteprojetos das Comissões Temáticas. Brasília, DF: Centro Gráfico do Senado Federal, 1987b.

BRASIL. Lei nº. 7. 716, de 5 de janeiro de 1989. Define os crimes resultantes de preconceito de raça ou de cor. Diário Oficial [da República Federativa do Brasil], Brasília, DF, 6 jan. 1989. Disponível em: <http://www6.senado.gov.br/legislacao/ ListaTextolntegral.action?id=109892>. Acesso em: 18 mar. 2008.

BRASIL. Lei n. ${ }^{\circ}$ 9.394, de 20 de dezembro de 1996. Estabelece as diretrizes e bases da educação nacional. Diário Oficial [da República Federativa do Brasil], Brasília, DF, 23 dez. 1996. Disponível em: <http://www.mi.gov.br/conade2.htm>. Acesso em: 3 jun. 2007.

BRASIL. Lei n. 10.639, de 9 de janeiro de 2003. Altera a Lei no 9.394, de 20 de dezembro de 1996, que estabelece as diretrizes e bases da educação nacional, para incluir no currículo oficial da Rede de Ensino a obrigatoriedade da temática "História e cultura afro-brasileira", e dá outras providências. Disponível em:<http:/ /www.planalto.gov.br/ccivil/LEIS/2003/L10.639.htm>. Acesso em: 19 mar. 2008.

BRASIL. Ministério da Educação. Secretaria de Educação Continuada, Alfabetização e Diversidade. Orientações e ações para a educação das relações étnico-raciais. Brasília, DF, 2006.

CONSElHO NACIONAL DE EDUCAÇÃO (Brasil). Conselho Pleno. Parecer $n^{\circ}$. CNE/ CP 003/2004, de 10 de março de 2004. Diretrizes Curriculares Nacionais para a educação das Relações Étnico-Raciais e para o Ensino de História e Cultura AfroBrasileira e Africana. Revista Espaço Acadêmico, Maringá, PR, ano 4, n. 40, set. 2004. Disponível em:<http://www.espacoacademico.com.br/040/40pc_diretriz.htm>. Acesso em: 18 mar. 2008.

GOMES, J. B. B. A recepção do instituto da ação afirmativa pelo direito constitucional brasileiro. In: SANTOS, A. S. Ações afirmativas e combate ao racismo nas Américas. Brasília, DF: MEC, SECAD, 2005.

GOMES, N. L. A contribuição dos negros para o pensamento educacional brasileiro. In: SILVA, P. B. G.; BARBOSA, M. A. (Org.). O pensamento negro em educação no Brasil: expressões do movimento negro. São Carlos: Ed. da UFSCar, 1997.

GUIMARÃES, A. S. A. Como trabalhar com "raça" em sociologia. Educação e Pesquisa, São Paulo, n. 1, p. 93-107, 2003. 
GUIMARÃES, A. S. A. Depois da democracia racial. Tempo Social: revista de sociologia da USP, São Paulo, v. 18, n. 2, p. 269-287, nov. 2006.

- Notas sobre raça, cultura e identidade na imprensa negra de São Paulo e Rio de Janeiro, 1925-1950. Afro-Ásia, Salvador, n. 30, p. 247-269, 2003.

. Racismo e anti-racismo no Brasil. São Paulo: Fundação de Apoio à Universidade de São Paulo: Editora 34, 1999.

HALL, S. Da diáspora: identidades e mediações culturais. Belo Horizonte: Ed. UFMG; Brasília, DF: UNESCO no Brasil, 2003. 2005 . A identidade cultural na pós-modernidade. 10. ed. Rio de Janeiro: DP\&A, MUNANGA, K.; GOMES, N. L. O negro no Brasil de hoje. São Paulo: Global, 2006.

OLIVEIRA, F. Ser negro no Brasil: alcances e limites. Estudos Avançados, São Paulo, v. 18, n. 50, 2004.

OLIVEIRA, I. (Org.). A formação de profissionais da educação para a diversidade étnico-racial. In: MULLER, M. L. R.; PAIXÃO, L. P. Educação, diferenças e desigualdades. Cuiabá: EdUFMT, 2006.

POR uma política nacional de combate ao racismo e à desigualdade: marcha Zumbi dos Palmares contra o racismo, pela cidadania e pela vida. Brasília, DF: Cultura Gráfica e Ed., 1996.

ROSEMBERG, F.; PINTO, R. P. (Org.). Raça negra e educação. Cadernos de Pesquisa, São Paulo, n. 63, nov. 1987.

SANTOS, A. S. Ações afirmativas e combate ao racismo nas Américas. Brasília, DF: SECAD, MEC, 2005.

SEYFERTH, G. O conceito de raça e as ciências sociais. Rio de Janeiro: Depto. de Antropologia, Museu Nacional, 2001. Mimeografado.

SHIVA, V. Monoculturas da mente: perspectivas da biodiversidade e da biotecnologia. Trad. Dinah de Abreu Azevedo. São Paulo: Gaia, 2003.

SILVA, P. B. G. Pesquisa e luta por reconhecimento e cidadania. In: ABRAMOWICZ, A.; SILVÉRIO, V. (Org.). Afirmando diferenças: montando o quebra-cabeça da diversidade na escola. Campinas, SP: Papirus, 2005. 
SILVÉRIO, V. R. Ação afirmativa: percepções da "casa grande" e da "senzala". In: BARBOSA, L. M. A. et al. (Org.). De preto a afro-descendente: trajetos de pesquisa sobre o negro, cultura negra e relações étnico-raciais no Brasil. São Carlos: EdUFSCar, 2003.

A diferença como realização da liberdade. In. ABRAMOWICZ, A.; BARBOSA, L. M. A.; SILVÉRIO, V. S. (Org.). Educação como prática da diferença. Campinas, SP: Armazém do Ipê (Autores Associados), 2006.

A (re)configuração do nacional e a questão da diversidade. In: ABRAMOWICZ, A.; SILVÉRIO, V. R. SILVÉRIO, V. (Org.). Afirmando diferenças: montando o quebra-cabeça da diversidade na escola. Campinas, SP: Papirus, 2005.

SIQUEIRA, M. L. Intelectualidade negra e pesquisa científica. Salvador: EDUFBA, 2006.

SKIDMORE, T. E. Preto no branco: raça e nacionalidade no pensamento brasileiro. 2. ed. Rio de Janeiro: Paz e Terra, 1976.

Recebido em: 26/12/2007

Aceito para publicação em: 15/02/2008 